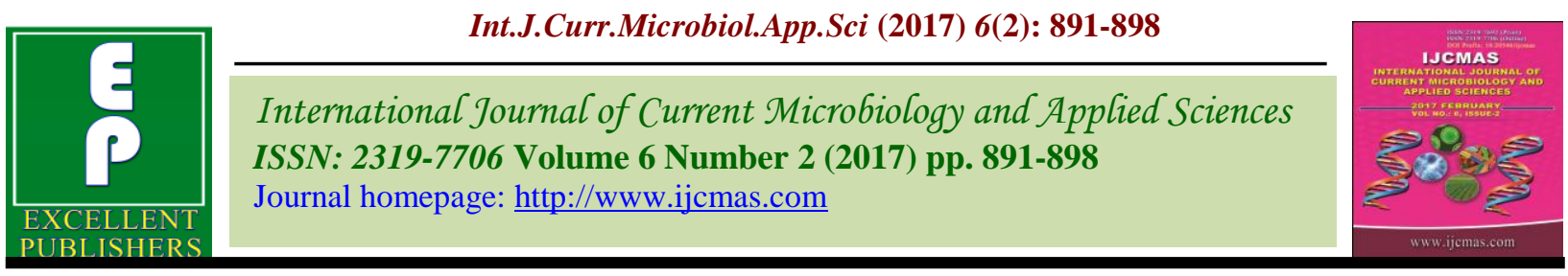

Original Research Article

http://dx.doi.org/10.20546/ijcmas.2017.602.099

\title{
Reaction of Grain Sorghum Varieties to Major Pests in Vidarbha Region
}

\author{
V.U. Sonalkar* and K.S. Pagire
}

All India Coordinated Sorghum Improvement Project, Sorghum Research Unit, Dr. Panjabrao

Deshmukh Krishi Vidyapeeth, Akola-444 104, India

*Corresponding author

\section{A B S T R A C T}

Keywords

Sorghum bicolor,

Shoot fly,

Stem borer,

Aphid,

Glossiness.

Article Info

Accepted:

18 January 2017

Available Online:

10 February 2017
A trial was carried out to evaluate the grain sorghum varieties for their reaction to major pests in advanced varietal experiment during kharif 2015 at All India Coordinated Sorghum Improvement Project, Sorghum Research Unit, Dr. PDKV, Akola. Nine sorghum varieties along with ten checks were screened for their reaction against shootfly, stem bore and aphids in randomized block design. The sorghum entry SPV 2296 expressed lowest shoot fly dead heart but not on par to resistant checks. The lines having low seedling glossiness score had positive highly significant (0.922) impact on shootfly dead hearts. The stem borer leaf injury rating and aphid damage score observed in the scale 1 to 9 each and were at low level. The association of stem borer leaf injury rating and aphid damage score with seedling glossiness was not significant and positively significant, respectively.

\section{Introduction}

Sorghum Sorghum bicolor (L.) Moench, one of the most important cereal crops is grown in Africa, Asia, United States of America, Australia and Latin America. Its importance after wheat, maize, rice and barley is because of its good adaptation to a wide range of ecological conditions, low input cultivation and diverse uses. In India, sorghum is grown on an area of 6.18 million ha with annual production of 5.28 million tonnes with productivity $845.4 \mathrm{~kg} / \mathrm{ha}$ in kharif and 674.7 $\mathrm{kg} / \mathrm{ha}$ in rabi season (FAO, 2014). Maharashtra, Karnataka, Madhya Pradesh, Andhra Pradesh and Rajasthan are the major states of the country growing the sorghum. In Maharashtra, it is grown on an area 36.78 lakh hectares with a production of 31.93 lakh tonnes and productivity of $868 \mathrm{Kg} / \mathrm{ha}$. In Vidarbha, it is grown on an area of 2.62 lakh hectare in kharif with a production 2.47 lakh tonnes with a productivity $943 \mathrm{~kg} / \mathrm{ha}$. Sorghum in the subtropics has a hostile environment where unreliable rainfall, poor soils, pests, diseases and weed constantly exert a harsh selection pressure. Insect pests are the major biotic constraints for production and productivity of sorghum. Among insects, shoot fly, Atherigona soccata (Order: Diptera, Family: Muscidae) is a major grain yield limiting factor that causes damage when the sowing is delayed and late sown crop is most affected. Besides, stem borer and aphids are insect pests that infest the crop in later stages. 
Shoot fly infestation decreases plant stand, and also causes severe losses in grain and fodder yield. Increase in shoot fly dead hearts by $1 \%$ results in a loss of $143 \mathrm{~kg}$ grain yield/ha, and an overall loss of $90-100 \%$ was reported under delayed sowings (Chundurwar and Karanjkar, 1979; Dhaliwal et al., 2004). The world wide yield loss due to shoot fly has been estimated to be over 274 million US\$ (Sharma 2006).In India, the losses due to shoot fly damage have been estimated to reach as high as $90 \%$ of grain, and $45 \%$ of fodder yield (Sukhani and Jotwani, 1979; Jotwani, 1982). In India, the annual economic losses in sorghum due to this pest have been estimated at US\$200 million (ICRISAT, 1992). Sugarcane aphid is found worldwide on many grass genera (Poaeceae). Sugarcane, Saccharum officinarum L., and sorghum are important cultivated hosts, and sugarcane aphid is an economic pest of sorghum in Asia, Africa, Australia, and South America (Singh et al., 2004). Along the Texas Gulf Coast and Louisiana in 2013, where abundant sugarcane aphid populations caused significant sorghum yield losses due to poor plant vigor and head emergence, and abundant honeydew affecting harvest efficiency (Villanueva et al., 2014). Heavy infestations with Melanaphis sacchari on sorghum at the booting and heading stages in central Taiwan reported by Chang and Fang (1984) reducing both grain quality and yield.

Shoot fly incidence is high in the late sown crop. Shoot fly incidence causes an average loss of 50 per cent in India (Jotwani, 1982), but the infestation at times may be over 90 per cent, (Rao and Gowda, 1967). Strategies adopted for management of sorghum shoot fly incidence include population dynamics, time of sowing, identification of resistant sources and development of cultivars and chemical control measures. Normal sowing is recommended so that the available residual moisture can be utilized fully and hence reduction in shoot flies infestation. However, many times it is not possible to adhere to this period because of variability in rainfall, non availability of seeds of improved varieties / hybrids, fertilizers, sowing implements, etc. in time. It causes staggered plantings which helps to increase the pest incidence. Adoption of chemical methods for control of shoot fly is not economically feasible for resource poor farmers. Use of resistant planting material in integrated pest management helps in minimizing the use of pesticides which results in conservation of natural enemies, prevention of environmental pollution and overcome the problem of development of insecticide resistant in insects. Host plant resistance combined with timely sowing is the most realistic approach to minimize the grain yield loss due to shoot fly.

Losses due to shoot fly damage can be reduced by using resistant varieties, timely planting, seed treatment with systemic insecticides, and need based application of foliar sprays during the seedling stage (Sharma, 1985). However, planting times in the semiarid tropics are dependent on the onset of rains, while the cost of insecticides restricts the poor farmers from applying them (Sharma, 1993). Therefore, host plant resistance (HPR) can be exploited as one of the most effective means of keeping shoot fly populations below the economic threshold levels (Sharma, 1985; Riyazaddin et al., 2015).

Resistance to shoot fly appears to be a complex trait. Non preference for oviposition is the primary mechanism of resistance to shoot fly. Ovipositional non preference and dead heart formation are related phenomena in the sense that less egg laying results in lower dead heart (Sharma et al., 1977). Glossy leaves possibly affect the quality of light reflected from leaves and influence the orientation of shoot flies towards their host plant. Therefore, the present study was undertaken with the objectives to determine 
the relative resistance of grain sorghum varieties to major pest of sorghum and to identify the new insect pest resistant grain sorghum variety.

\section{Materials and Methods}

In kharif 2015, a trial was laid in a randomized block design with three replications. In total nine grain sorghum entries in Advance Varietal Trial (AVT) along with 10 checks were tested. All entries were sown on $3^{\text {rd }}$ July 2015 in two rows of 2.0 $\mathrm{m}$ length by following a row spacing of $45 \mathrm{~cm}$ and $15 \mathrm{~cm}$ plant spacing. Intentionally, a trial was sown 20 days late than normal sowing with a view to have a maximum shoot fly intensity. Plant population of each entry was counted at 12 days after emergence (DAE) and seedling glossiness score was also recorded in 1-5 scale. Observations on dead hearts due to shoot fly were recorded by counting total plants and plant showing dead hearts due to shoot fly in each entry at $28^{\text {th }}$ days after emergence. The per cent dead hearts caused by shootfly were worked out for each entry. The data on per cent dead hearts was converted to arc sine transformations and analyzed statistically. Stem borer leaf injury rating in the scale 1 to 9 was recorded at 35 DAE. The aphid leaf damage was assessed at milk stage in the scale 1.00 to 9.00 .

\section{Results and Discussion}

\section{Plant stand and seedling glossiness score at} 12 DAE

Plant population in entries was ranging from 20.33 to 27.33 plants per two rows of two meter (Table 1). Seedling glossiness score was lowest i.e. 1.0 in resistant checks IS 18551 and IS 2205(1.67). Besides these, none of the entries scored less than 3.0 glossiness score. The test entries SPV 2293, SPV2294 and SPV 2296 scored 3.00 seedling glossiness. The highest glossiness i.e. 5.0 has scored by test entry SPV 2305. The check entry SPV 669 (4.67) scored next highest glossiness and susceptible check entry viz., Swarana, DJ 6514 and ICSV 745 scored 4.33glossiness each. Two entries including one check and one test entry SPV 2296 and CSV 17 scored seedling glossiness score 4.00. Shyam Prasad et al., (2014) observed seedling glossiness score in 32 entries and found glossiness range 1.8 to 4.6 with low values for resistant checks. Stepwise regression indicated that 90.4 per cent of the total variation in dead hearts was due to leaf glossiness (Dhillon et al., 2005).

\section{Shoot fly dead hearts at 28 DAE}

The incidence of shoot fly was assessed in the form of dead hearts symptoms observed on $28^{\text {th }}$ days after emergence. At this stage dead hearts was at high level i.e. up to 93.67 percent. Under such high population pressure; resistant check entries expressed resistance with least dead hearts. The resistant check, IS 18551 and IS 2205 had 5.04 and 4.89 percent dead hearts, respectively and rest of the entries had more than 59 percent dead hearts except entry SPV 2296. Among the nine test entries SPV 2296 expressed comparatively good reaction with 34.14 percent dead hearts however, this was not on par to dead hearts in resistant checks (Table 1 and Fig. 1). The highest dead hearts were in susceptible check Swarna (93.67\%) lines followed with 92.07, 90.55 and 88.80 per cent in susceptible checks ICSV 745, SPV 669 and DJ 6514, respectively. The test entries viz., SPV 2294 (59.94\%), SPV 2293 (60.58 \%), SPV 2308 (60.76\%), SPV $2298(60.87 \%)$, SPV 2250 $(61.24 \%)$ and SPV 2307 (63.78\%) has significantly least shoot fly dead hearts than the dead hearts in susceptible checks. Shyam Prasad et al., (2014) screened 32 sorghum lines for shootfly resistance and observed 16 lines on par shoot fly dead hearts to resistance is a cumulative/combine effect of nonpreference and antibiosis (Raina et al., 1981). 


\section{Stem borer leaf injury rating}

Test entry SPV 2305 and check entries DJ 6514 and Swarna scored stem borer leaf injury score 1.00 . None of the entry crossed stem borer leaf injury score 3.00 and above.
Under such low stem borer incidence pressure, highest of 3.00 damage score expressed by test entry SPV 2296 followed by SPV 2293 (2.33). Test entries SPV 2250, SPV 2294, SPV 2298, SPV 2307, SPV 2308 expressed each 1.33 leaf injury score.

Table.1 Reaction of sorghum varieties in Advance Varietal Trial (AVT) to major insect pests kharif 2015

\begin{tabular}{llllcccc}
\hline \multirow{2}{*}{ SN } & \multirow{2}{*}{ Sorghum Entry } & Plant & \multirow{2}{*}{ SGS } & \multicolumn{2}{c}{ SF-DH (\%) } & \multirow{2}{*}{ SB-LIR } & $\begin{array}{c}\text { Aphid } \\
\text { Score }\end{array}$ \\
\hline 1 & SPV 2250 & 25.00 & 3.33 & 61.24 & $(51.56)$ & 2.00 & 2.00 \\
2 & SPV 2293 & 25.67 & 3.00 & 60.58 & $(51.47)$ & 2.33 & 2.00 \\
3 & SPV 2294 & 25.33 & 3.00 & 59.94 & $(51.02)$ & 2.00 & 2.00 \\
4 & SPV 2296 & 26.33 & 3.00 & 34.14 & $(35.74)$ & 3.00 & 1.67 \\
5 & SPV 2298 & 24.33 & 3.33 & 60.87 & $(52.36)$ & 2.00 & 1.67 \\
6 & SPV 2299 & 21.00 & 4.00 & 84.39 & $(67.61)$ & 1.67 & 1.33 \\
7 & SPV 2305 & 20.33 & 5.00 & 93.53 & $(75.40)$ & 1.00 & 2.33 \\
8 & SPV 2307* & 25.33 & 3.33 & 63.78 & $(53.91)$ & 2.00 & 1.00 \\
9 & SPV 2308* & 23.33 & 3.33 & 60.76 & $(51.64)$ & 2.00 & 1.00 \\
10 & CSV 17 & 23.67 & 4.00 & 84.47 & $(66.83)$ & 2.00 & 1.33 \\
11 & CSV 20 & 25.67 & 3.33 & 66.50 & $(54.73)$ & 2.00 & 1.33 \\
12 & CSV 23 & 25.67 & 4.33 & 63.16 & $(53.06)$ & 1.67 & 1.33 \\
13 & CSV 27 & 24.33 & 3.33 & 80.78 & $(64.79)$ & 2.00 & 1.33 \\
14 & SPV 669 & 20.33 & 4.67 & 90.55 & $(72.21)$ & 2.00 & 1.67 \\
15 & IS 18551 & 26.33 & 1.00 & 5.04 & $(12.81)$ & 1.67 & 1.00 \\
16 & DJ 6514 & 26.00 & 4.33 & 88.80 & $(71.44)$ & 1.00 & 2.00 \\
17 & IS 2205 & 27.33 & 1.67 & 4.89 & $(12.59)$ & 1.33 & 1.00 \\
18 & Swarna & 25.00 & 4.33 & 93.67 & $(78.53)$ & 1.00 & 1.67 \\
19 & ICSV 745 & 24.67 & 4.33 & 92.07 & $(73.91)$ & 1.67 & 2.33 \\
\hline & SE(m) \pm & & & & 5.70 & & \\
& CD at 5\% & & & & 16.36 & & \\
& CV (\%) & & & & 17.85 & & \\
\hline
\end{tabular}

Note: SGS, Seedling glossiness score; SF-DH, Shoot fly dead hearts; SB-LIR, Stem borer leaf injury rating; figures in parentheses are arc sin values. 
Table.2 Correlation between seedling glossiness and insect pests incidence

\begin{tabular}{cccc} 
Plant trait & SF-DH $(\%)$ & SB-LIR & Aphid Score \\
\hline Seedling glossiness & $0.922^{* *}$ & -0.285 & $0.519^{*}$
\end{tabular}

Correlation coefficients (r) significant at $5 \%(0.456)$ and $1 \%(0.575)$

Fig.1 Percent shootfly dead hearts of various sorghum lines

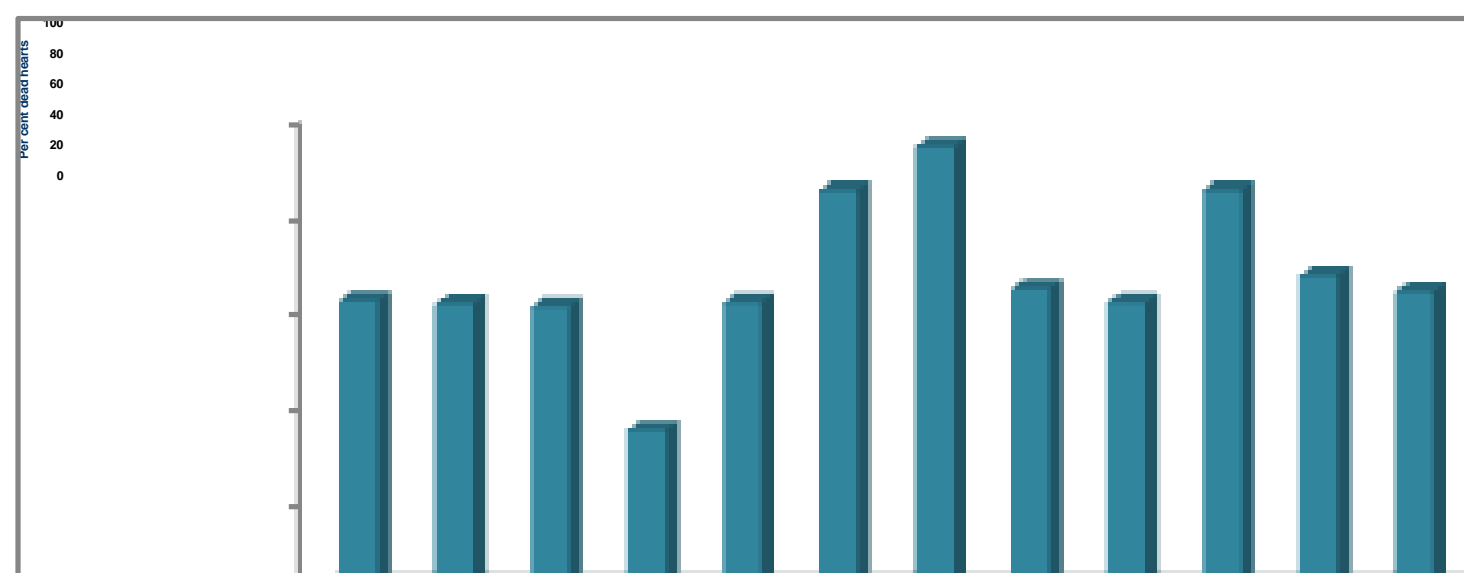

Shyam Prasad et al., (2014) reported the mean leaf damage score 6.1 which ranged from 4.0 to 8.0. The genotype IS 7550, IS 7553, E 27, ICSR 93034 and SSV 84 showed heavy leaf damage. Most of the genotypes were susceptible recording damage score above 6.0. The lines ICSV 93046, GGUB 57 and PVR 453 were on par with RC IS 2205 which recorded low leaf damage score of 4.0 suggesting that low larval establishment in the whorl leaves (Davis 1985) and antibiosis are the major components of resistance to $C$. partellus in these genotypes. Low leaf feeding and low larval establishment are important components of resistance to $C$. partellus in sorghum (Van den Berg and Westhuizen, 1988).

However, Starks and Doggett (1970) suggested that leaf feeding by $C$. partellus in sorghum is a poor indicator of expected grain yield as production of newer leaves may compensate the leaf damage. Loss in photosynthetic leaf area causes reduction in leaf size and results in reduced plant vigour. In the present investigation stem borer leaf injury score was recorded at low level. Study calculated by Prasad et al., (2015) regarding stem borer leaf injury score indicated higher score at Hyderabad might be due to the region specific damage by the pest.

\section{Aphid damage score}

Aphid damage score was at low level in the scale 1 to 9 within sorghum lines. The least of 1.00 damage score observed for two check entries i.e. IS 18551 and IS 2205. Among the test entries minimum i.e. 1.00 damage score was for SPV 2307 and SPV 2308. Highest damage score 2.33 was expressed by test entry SPV 2305 followed by check entry ICSV 745. 
In Maharashtra, Ghugusker et al., (1999) tested 26 hybrids, 22 of which were new hybrids CSH 16 and 9728 were observed resistance to aphid. Teetes et al., (1995) screened seedlings of 462 sorghum lines for resistance to sugarcane aphid and he observed that 7 per cent of the lines exhibited resistance in the seedling stage in green house trials, further tested in advanced screening experiments, twelve sorghum lines observed resistance ratings of 1.0 to 3.0. Chang and Fang (1984) in central Taiwan studied resistance of 53 lines and 42 crosses in field tests in the spring of 1982, they found that 3 of the lines (R-128, R-131 and R-133) and 2 of the crosses $(71-4$ and $80 \mathrm{~A} \times 330 \mathrm{R})$ were found to be resistant.

Balikai and Biradar (2007) Evaluated twenty sorghum parental lines along with a resistant and susceptible check were evaluated for their resistance to aphid. The parental lines viz., AKR 150, C 43, R 354, RS 29 and Indore 12 were categorized as resistant to aphids which scored less than 2 grade.

\section{Association of SGS and insect pest incidence}

The seedling glossiness score in early growth stage during shootfly oviposition period could affect the shoot fly dead hearts symptoms. The glossiness seedlings i.e. the lines having low seedling glossiness score had positive highly significant (0.922) impact on shootfly dead hearts (Table 2).

Leaf glossiness acts mainly as non-preference mechanism. The intensity of leaf glossiness at the seedling stage is positively associated with level of resistance to shoot fly (Dhillon et al., 2006; Gomashe et al., 2010; Chamarthi et al., 2011). Highly significant and positive correlation between shoot fly and glossiness (0.71) was reported by Chikkarugi (2007). The leaf injury done by stem borer was recorded on leaves of sorghum lines 35 days after emergence and aphid damage 45 days after emergence in the scale 1 to 9 . The stem borer leaf injury within sorghum lines was at low level (Table 1). This low stem borer leaf injury data correlated with seedling glossiness. The aphid damage score positively affected by seedling glossiness (Table 2).

\section{References}

Balikai, R.A. and B.D. Biradar. 2007. Field evaluation of sorghum parental lines for resistance to shoot fly and aphid. Agric. Sci. Digest, 27(4): 14-17.

Chamarthi, S.K., H.C. Sharma, K.L. Sahrawat, L.M. Narasu and M.K. Dhillon. 2011. Physico-chemical mechanisms of resistance to shoot fly, Atherigona soccata in sorghum, Sorghum bicolor. J. Appl. Ent., 135: 446-455.

Chang, C.P., Fang, M. N.1984Studies on the resistance of sorghum varieties to the sorghum aphid, Melanaphis sacchari (Zehntner). Chinese J. Entomol., Vol.4 (1): 97-105.

Chikkarugi N. 2007. Studies on multiple resistance and management of sorghum pests in rabi. M.Sc. thesis submitted to the University of Agricultural Sciences, Dharwda.

Chundurwar R.D., R.R. Karanjkar. 1979. Effect of shoot fly infested levels on grain yield of sorghum hybrid CSH-8R. Sorghum Newsletter, 22: 70.

Davis, F.M. 1985. Entomological techniques and methodologies used in research programs on plant resistance to insects. Insect Sci. Appli., 6: 391-400.

Dhaliwal, G.S., Arora Romesh, Dhavan, A.K. 2004. Crop losses due to insectpests in Indian agriculture, Anupdate, Indian J. Ecol., 31: 1-7.

Dhillon, M.K., H.C. Sharma, B.V.S. Reddy, Ram Singh and J.S. Naresh. 2006. 
Inheritance of resistance to sorghum shoot fly (Atherigona soccata Rond). Crop Sci., 46: 1377-1383.

Dhillon, M.K., H.C. Sharma, Ram Singh, and J.S. Naresh. 2005. Mechanisms of resistance to shoot fly, Atherigona soccata in sorghum. Euphytica, 144: 301-312.

FAO. 2014. Food and Agriculture Organization of the United Nations.

Ghuguskar, H.T., R.V. Chaudhari and N.V. Sorte, 1999.Evaluation of sorghum hybrids for tolerance to aphids, Melanaphis sacchari (Zehntner) in field conditions. PKV Res. J., 23 (1): 55-56.

Gomashe S., M.B., K.N. Misal, Ganapathy and SujayRakshit, 2010. Correlation studies for shootfly resistance traits in sorghum (Sorghum bicolor (L.) Moench), Electronic J. Plant Breeding, 1(4): 899-902.

ICRISAT. 1992. The medium term plan, vol 2.International Crops Research Institute for the Semi-Arid Tropics, Patancheru 502 324, Andhra Pradesh, India.

Jotwani, M.G. 1982. Factor reducing sorghum yields -Insect pests. In: L. R. House, L. K. Mughogho and J. N. peacock (Eds), Sorghum in eighties, Proceedings of the International symposium on sorghum, 2-7 November, 1981, pp. 251-255. International Crop Res. Institute for Semi Arid Tropics, patencheru, 502324, Andhra Pradesh.

Jotwani, M.G., W.R. Young and G.L. Teete, 1980. Elements of integrated control of sorghum pests.FAO, Food and Agricultural Organization, Rome, Italy. Plant Protection and Production Paper no. 39:159.

Prasad, G.S., K. Srinivasa Babu, B. Subbarayudu, V.R. Bhagwat and J.V. Patil. 2015. Identification of sweet sorghum accessions possessing multiple resistance to shoot fly (Atherigona soccata Rondani) and Spotted Stem
Borer (Chilopartellus Swinhoe). Sugar Tech, (Apr-June 2015) 17(2): 173-180.

Raina, A.K., H.K. Thindwa, S.M. Othieno, and R.T. Cork Hill. 1981. Resistance in sorghum to the sorghum shoot fly: larval development and adult longevity and fecundity on selected cultivars, Insect Sci Appli., 2: 99-103.

Rao, M. and S. Gowda. 1967. A note on the bionomics and control of jowar fly. Sorghum News let., 10: 55-57.

Riyazaddin M.D., P.B. KaviKishor, A. Ashok Kumar, V.S. Belum Reddy, S.M. Rajendra, H.C. Sharma, 2015. Mechanisms and diversity of resistance to sorghum shoot fly, Atherigona soccata, Plant Breed, 134(4): 423-436.

Sharma H.C. 1985. Future strategies for pest control in sorghum in India. Trop. Pest Manag, 31:167-185.

Sharma, H.C. 2006. Integrated pest management research at ICRISAT: present status and future priorities. International Crops Research Institute for the Semi-Arid Tropics (ICRISAT), Patancheru, Andhra Pradesh, India: 48.

Sharma, G.C., M.G. Jotwani., B.S. Rana and N.G.P. Rao. 1977. Resistance to the sorghum shoot fly, Atherigona soccata (Rondani) and its genetic analysis. $J$. Entomol. Res., 1(1): 1-12.

Sharma, H.C. 1993. Host-plant resistance to insects in sorghum and its role in integrated pest management. Crop Pro., 12: 11-34.

Shyam Prasad, G., K. SrinivasaBabu, B. Subbarayudu, V.R. Bhagwat, J.V. Patil., 2014. Identification of Sweet Sorghum Accessions Possessing Multiple Resistance to Shoot Fly (Atherigona soccata Rondani) and Spotted Stem Borer (Chilopartellus Swinhoe), Sugar Tech. doi: 10.1007/s 12355-013-0299-5.

Singh, B.U., Padmaja, P.G., Seetharama, N. 2004. Biology and management of the sugarcane aphid, Melanaphis sacchari 
(Zehntner) (Homoptera: Aphididae), in sorghum: a review. Crop Protection, 23: 739-755.

Starks, K.J., and H. Doggett. 1970. Resistance to spotted stem borer in sorghum and maize. J. Economic Entomol., 63: 17901795.

Sukhani, T.R. and M.G. Jotwani. 1979. Effects of site of oviposition on shoot fly damage to different growth stages of sorghum seedling, Ind. J. Entomon., 41: 366-370.

Teetes, G.L., C.S. Manthe, G.C., Peterson, K. Leuschner and B.B. Pendleton. 1995. Sorghum resistant to the sugarcane aphid, Melanaphis sacchari
(Homoptera: Aphididae) in Botswana and Zimbabwe, Insect Sci. Applic., 6(1): 63-71.

Van den Berg, J., and M.C. Van der Westhuizen. 1988. The effect of resistant sorghum hybrids in suppression of Busseolafusca Fuller and Chilopartellus (Swinhoe) populations, Insect Sci. Appli., 18: 31-36.

Villanueva, R.T., Brewer M.J., Way, M.O., Biles, S., Sekula, D., Bynum E., Swart, J., Crumley, C., Knutson, A., Porter P., et al., 2014. Sugarcane aphid: a new pest of sorghum. Texas A\&M Agrilife Extension, Ento-035, College Station, TX. 4 p.

\section{How to cite this article:}

Sonalkar, V.U., and Pagire, K.S. 2017. Reaction of Grain Sorghum Varieties to Major Pests in Vidarbha Region. Int.J.Curr.Microbiol.App.Sci. 6(2): 891-898.

doi: http://dx.doi.org/10.20546/ijcmas.2017.602.099 